\title{
ON RATES OF MORTALITY AND WITHDRAWAL.
}

To the Editor of the Journal of the Institute of Actuaries.

SIR,-The interesting letters from Mr. Todhunter and Mr. Burn, upon the above general subject, which appeared in your last issue (pp. 273-80), demand from me some lines by way of response and acknowledgment.

\section{Discontindances.}

Mr. Todhunter's letter appears to me to be an extremely valuable and opportune contribution to the discussion of this subject. I am in entire agreement with his arguments and conclusions as to the characteristic distinction between the rate of withdrawal (or nonrenewal) and that of mortality, the former being in the nature of a discontinuous or periodic force, the latter of a continuous or momentary force. I am also disposed to think that the calculation of rates of non-renewal (as proposed by $\mathrm{Mr}$. Todhunter) will be likely more truly to represent the real force of discontinuance than the computation of rates of withdrawal as ordinarily understood, and as worked out in my recent paper. I may add, that consideration of Mr. Todhunter's arguments, and the opportunities I have recently had of practically investigating a large body of data, lead me to attach less importance to the strict tabulation of withdrawals in their true years of duration, although I still think this a desirable course.

As regards the applicability of the Nearest Duration Method to the calculation of rates of non-renewal, I am also in accord generally with Mr. Todhunter, but subject to the reservation that, especially in the case where the "days of grace" are included in the term of the exposure, the method seems hardly to give satisfactory results in the early years of assurance. I think it will be found that some simple modification of the method can be devised, which shall give better effect in such a case to the incidence of the withdrawals in the early years, and this would be, I think, preferable (in the case where "days of grace" are included) to an application of the ordinary method over quarterly periods. It seems, however, very desirable to tabulate the withdrawals for statistical purposes at quarterly epochs during the early years of assurance, in order to give all needed data for investigations relating to the effect of withdrawal and of selection.

\section{Mr. King's In'ter-Vatuation Formula for Exposed to Risk.}

Mr. Burn appears to be under some misapprehension as to the intention and purport of some remarks contained in my recent paper bearing on this interesting method. I had no intention of offering any general criticism upon Mr. King's method, and, indeed, I expressly stated at the outset (J.I.A., xxxiii, 70) that, while "doubtless admirably adapted for the purposes designed by its author", this method would not (for reasons which had nothing to do with its merits) lend itself to my particular purposes. But in a special section of my paper, dealing solely with the various methods proposed for determining the ages at entry, I discussed, amongst 
others, Mr. King's particular assumptions in this respect, and it was with regard to this alone that $I$ arrived at the conclusion that, while the method "would probably give on the whole good results", it was "clearly inferior" (solely as regards the determination of the age at entry) "to the method of nearest ages" (J.I.A., xxxiii, 134).

With Mr. Burn's remarks as to the general merits of Mr. King's method I am in hearty and entire accord, but I fail to see the force of his arguments, and I certainly do not agree with his conclusions, as to the possible error in the age at entry as tabulated. I agree with Mr. Burn that the deviation, in an individual case, between the true age at entry and that at which the risk is, by $\mathbf{M r}$. King's method, assumed to commence, is made up of two component parts:(1) The interval between date of entry and nearest 31 December, which cannot exceed six months; (2) The interval between the 31 December so selected and the then nearest birthday, whichalso cannot exceed six months; and it is admitted, and has indeed been demonstrated by Mr. Whittall, that the date of entry and the birthday can so fall as to produce, by the combination of these two deviations, an interval of a year between the true and assumed entry ages. But Mr. Burn seems to suggest that the first of these deviations should be ignored, and the second only taken into account, in determining the error in the age at entry; and this (apparently) upon the ground that the life is considered as entering on the selected 31 December.

I would suggest that, in ascertaining the true deviations in the age, we are bound to give full effect to the facts, and are not entitled to shift the date of entry from the real point to an assumed or imaginary one.

Mr. Burn further says that I " saddle the whole of the error on to the age, without making any mention of the duration." But Mr. King's method, as Mr. Whittall has pointed out (xxxi, 185), "rejects durations of all sorts"; the only data tabulated being the age at commencement and the age at termination of the risk, between which the duration (inferentially) lies; and I can see no legitimate way of arriving at the difference between the real and assumed age at entry, in an individual case, other than by comparing the true age at entry and that assumed for commencement of the risk.

I would further suggest that Mr. Burn's argument confuses average and individual deviations, and that it is not strictly correct to say that in an individual case the date of entry is considered to be the nearest 31 December. The assumed date of entry is surely that recorded and tabulated, namely, the birthday nearest to the selected 31 December. In a great number of cases, the birthdays so chosen will tend to group equally over the six months preceding and following the selected 31 December, and we are thus entitled to say that, on the average, the cases are considered as entering at 31 December, but this conclusion is surely not applicable to an individual case.

It seems to me that Mr. Burn's argument could as legitimately be applied to the Nearest Age Method, pure and simple, by suggesting that the cases can all be "considered" as entering at their nearest birthdays, and that as the cases are all tabulated at those birthdays, there is really no possible error in the age at entry. But this would 
be a reductio ad absurdum, and I think, therefore, there must be some fallacy in Mr. Burn's line of argument.

The particular case cited by him is one of those giving a deviation of a year in the age at entry, and if the case also withdraw during the period of observation, there may be a deviation of a year in the age at exit, in the same, or in a contrary, direction. The following table gives eight typical cases of extreme deviation:

\section{Inter-Valuation Period (say) 1 January 1890-31 December 1894.}

\begin{tabular}{|c|c|c|c|c|c|}
\hline \multirow{2}{*}{ Date of Birth } & \multirow{2}{*}{$\begin{array}{l}\text { Date of } \\
\text { Entry }\end{array}$} & \multirow{2}{*}{$\begin{array}{c}\text { Date of } \\
\text { Exit }\end{array}$} & \multicolumn{2}{|c|}{ Age at Assumed } & \multirow{2}{*}{$\begin{array}{l}\text { Assumed } \\
\text { Duration }\end{array}$} \\
\hline & & & Entry & Exit & \\
\hline (1) 30.6.'50 & $1.7 . ' 90$ & 1.7.'93 & 41 & 44 & 3 \\
\hline (2) 30.6.'50 & $1 \cdot 7.900$ & $30.6 .^{\prime} 93$ & 41 & 43 & 2 \\
\hline (3) $\{30.6 .50$ & $\begin{array}{l}\text { 29.6.'90 } \\
30.6,90\end{array}$ & 1.7.'93 & 40 & 44 & 4 \\
\hline (4) 1.7 .50 & 30.6 .90 & 30.6 .93 & 39 & 42 & 3 \\
\hline $1.7 . ' 50$ & 30.6 .90 & 1.7.'93 & 39 & 43 & 4 \\
\hline (c) 1.7 .50 & 2.7.'90 & $30.6 .^{\prime} 93$ ) & 40 & 49 & 9 \\
\hline (0) $\imath$ 2.7.'50 & 1.7.'90 & 30.6.'93 & fiv & 42 & 2 \\
\hline
\end{tabular}

The true age at entry is, in each of these eight cases, 40 , the true age at exit is 43 , and the true duration 3 years. If these ages and durations represent the correct application of Mr. King's formula, it appears to me impossible to avoid the conclusion that the age at entry, the age at exit, and the duration, can each be distorted by a full year more or less, and this does not at all bear out Mr. Burn's conclusion, that the ages taken "coincide throughout with the nearest age of the life."

It will be observed that the deviations in cases (1), (2), (3) are complementary to those in cases $(4),(5),(6)$ respectively, and that the average of the whole gives a true result throughout, assuming that the numbers entering of each class are respectively equal.

The whole of the above remarks apply solely to cases entering during the period of observation. The large body of eases which pass through the commencement of the period as "survivors", and also those which pass through the termination of the period as cases "existing", are strictly tabulated according to their nearest ages at entry or exit, with a maximum deviation of six months, and it is only the cases entering, or emerging as withdrawals, during the period, that give rise to greater deviations either in the age at entry, the age at exit, or the duration.

As regards entrants, also, the maximum deviation is, when they pass into a new period of observation as "survivors", ingeniously and automatically, as it were, reduced to a deviation not exceeding six months. The method thus, in many respects, compares favourably with the nearest age method; but with greater possible individual deviations in respect of the "movement" of the period. Each deviation, large or small, has a compensatory deviation, with contrary 
sign, and, so far as the cases with such compensating errors may be considered equal in their number and incidence, the method will give, in the aggregate, closely accurate results.

The cases of death are rather puzzling, because it is somewhat difficult to determine upon the proper standard of comparison to be applied in testing the accuracy of the age at exit. This may be done by comparing the age at death as tabulated ("nearest age to 31 December preceding death") with either-

(1) The age at policy-anniversary preceding death;

(2) The age at 31 December preceding death;

(3) The age at birthday preceding death.

In the case of "survivors" dying within the period, $\mathrm{Mr}$. King's method of dealing with the age at death seems to be the mostappropriate, and the standard of comparison appears in this case to be the true age at 31 December preceding death, which gives in this class a maximum deviation of six months, and a curtate duration represented in calendar years.

In respect of cases both entering and dying within the period, the policy-anniversary standard (1) seems to be the most appropriate, but in these cases the deviation in the age at exit may considerably exceed six months. It has also been pointed out that in some cases the assumed age at entry may exceed the assumed age at death. This appears to arise from the method followed in estimating the age at death, which altogether ignores the policy-anniversary, and a simple modification of the method would seem (if otherwise admissible) to avoid this inconsistency of result. If in this particular class of cases entering and dying within the period, we take the age at death as the nearest age to 31 December nearest to the policy-anniversary preceding death, the age at exit, as assumed, can never be less than the assumed age at entry, and the difference will always represent (as it seems to me it should do) the true curtate duration of the policy. Under this suggested modification, however, the deviation in the age at exit, although somewhat reduced, can still exceed six months, and this seems to be unavoidable, in this particular class, by any modification of $\mathbf{M r}$. King's methods.

An alternative method would be to treat as a distinct class the cases which both enter and emerge (whether by withdrawal or death) during the period of observation; and to tabulate, in this class, the entrants, at nearest ages at entry; the withdrawals, at nearest ages at exit; and the deaths, at nearest ages to the policy-anniversaries preceding death. The deviations in the respective ages could then never exceed six months; and the death cases would be tabulated, throughout, at their true curtate durations. It seems to be permissible to treat these cases of entry and exit as a separate class, and by a distinct method, as these particular cases have (as Mr. King has pointed out, xxvii, 219) to be separately abstracted and classified, and are not derived directly from the valuation class-books; and it is, moreover, in this particular class that the maximum deviations arise.

Upon the whole, I consider that the method is admirably devised for the special purpose intended by its author, namely, the investigation of the mortality of an inter-valuation period at ages passed 
through, and I cordially endorse Mr. Burn's conclusion that it is " undoubtedly the best which has as yet been suggested for this particular purpose."

\section{Tabulation of Endowment Assurances.}

Mr. Meikle, in his very interesting remarks in the course of the discussion upon my recent paper, called attention (xxxiii, 201-2) to some difficulties arising in the tabulation of endowment assurances, as regards the ages at maturity, and suggested that policies maturing at, say, 50 years of age, might, by certain applications of the Nearest Duration Method, be tabulated as maturing either at 49, 50, or 51 . This is no doubt the case, but it will, I think, be found to depend upon the method adopted in estimating the ages at entry, and if the method be that of ages next birthday, or ages last birthday, or mean ages, the discrepant results indicated by Mr. Meikle will follow. I think it will, however, be found that where the nearest age at entry (Dr. Sprague's "commencing age") is combined with the nearest integral duration, the age at maturity will in all cases be represented accurately or to the nearest integer. So far as I know, the office practice as regards endowment assurances is to fix the maturity either $(a)$ on a definite birthday, when the duration of the policy is fractional; or $(b)$ on the policy-anniversary nearest to, or else next preceding, the selected birthday, when the duration is an integral number of years. In the case $(b)$ it is evident that the deviation of the age at maturity (the duration being integral) will be identical with that of the age at entry, and if the latter is the nearest age at entry, the age at maturity, as tabulated, will be the nearest age at maturity. This may be 49 or 51 in the case of a policy nominally maturing at 50 , but only where the policy really matures at a point nearer to 49 or 51 than to 50 .

In the case $(a)$ of payment on attainment of a birthday, if we assume that the office age next birthday is $x$ and the true age at entry is either $(x-\phi)$ or $(x-1+\phi)$, where $\phi$ is a fraction $<\frac{1}{2}$, we have the following results respectively:

\section{Policy payable on $(x+t)$ th birthday.}

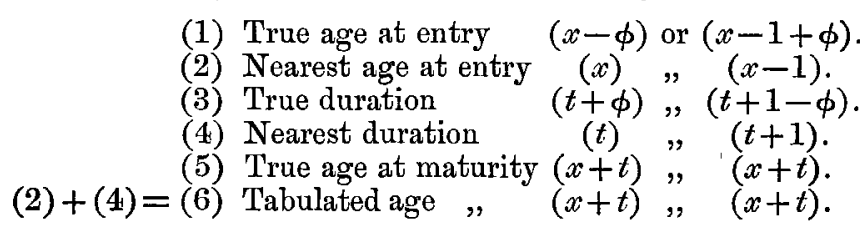

The assumed and true ages at maturity will thus be identical. The only case of possible doubt would be where the true age at entry was exactly half-way between two birthdays, so that $\phi=\frac{1}{2}$; in that case, care would have to be taken that, if the nearest age at entry is written up, the nearest duration is written down, and vice versâ.

I do not imagine that Mr. Meikle is referring to this exceptional case, but rather suppose that there may be other varieties of office 
practice, as regards duration and epoch of maturity, which are unknown to me, but which his much larger experience has brought under his notice, and in which the discrepant results referred to may arise. It would, however, appear that where the assurance matures either on a birthday or on a policy-anniversary, the combination of the nearest age at entry and the nearest duration will always give the age at maturity correctly, or to the nearest age.

\section{Dupuicates.}

Mr. Meikle also refers to the fact that, by the Nearest Duration Method, cases upon the same life may be recorded as both "existing" and terminating by death. This arises where the period of observation is closed on the policy-anniversary in a certain calendar year, so that, in the case of two or more assurances upon one life, the assured, if dying between the policy-anniversaries in the closing calendar year, would appear as "existing" under some of the assurances, and as "dead" under others.

'This difficulty appears, however, to arise solely from the limitations fixed in ascertaining the data, and not from the particular method of tabulation adopted.

I am, Sir,

Yours obediently,

THOMAS G. ACKLAND.

Croydon,

I June 1897.

\section{ON THE CALCULATIONS OF GEORGE BARRETT IN THE EARLY PART OF THIS CENTURY.}

To the Editor of the Journal of the Institute of Actuaries.

Sir,-Some calculations of George Barrett have recently passed through my hands, in my capacity as one of the Librarians of the Institute, containing some original details and notes which, I think, may be interesting to the readers of our Journal. The calculations have been placed at the disposal of the Institute by the London Life Association, through the kindness of Mr. C. D. Higham.

As is well known, Barrett introduced the use of Commutation Columns into England. Very little is known of him beyond the particulars given in a paper by De Morgan in vol. iv. of the Journal. In the rough calculations under notice, by far the greater part are folio sheets, covered both sides to the edges with figures, and as the final values are alternate with the subsidiary elements of the calculations, the arguments being very indistinct, no purpose would be served in having the sheets bound into volumes, as the Institute Library already possesses Barrett's Final Tables based on these calculations, hereafter referred to.

Barrett was assisted by his sister and a niece in the work, though everything was finally checked by himself and initialled. He does not appear to have been so happy in a male helper, as there is a remark at the foot of one page-" Note. The person whom I got 